\title{
Testing of Device from Same Lot/Batch Returned from User
}

National Cancer Institute

\section{Source}

National Cancer Institute. Testing of Device from Same Lot/Batch Returned from User.

NCI Thesaurus. Code C139447.

The investigation employed relevant empirical testing of the device of the same lot or batch than that of the suspected device in the reported adverse event in order to support the identification of possible causes for the adverse event. The device was returned from the user. Relevant testing would typically be based on test methods used for evaluating safety and performance as described in the latest relevant standards. 